УДК 811.133.1

ББК 81.471.1

DOI: https://doi.org/10.17308/lic.2021.2/3416

\title{
СПОСОБЫ ВЕРБАЛИЗАЦИИ ПРЕДМЕТНЫХ ОТНОШЕНИЙ В ЯЗЫКОВОЙ КАРТИНЕ МИРА (НА МАТЕРИАЛЕ ФРАНЦУЗСКОГО И РУССКОГО ЯЗЫКОВ)
}

\author{
А. А. Чвирова \\ Воронежский государственный университет
}

\section{MEANS OF VERBALIZATION OF SUBJECT RELATIONS IN LINGUISTIC PICTURE OF THE WORLD (BASED ON MATERIAL FROM FRENCH AND RUSSIAN LANGUAGES)}

\author{
A. A. Chvirova \\ Voronezh State University
}

\begin{abstract}
Аннотация: языковая картина мира представляет собой совокупность накопленных человеком знаний о мире, представленных в языковой форме. Находясь в окружении предметов, человек отражает свои отнотения с предметами и отношения между предметами различными языковыми средствами в рамках своей языковой картины мира. В настоящей статье исследуются способы синтаксической вербализации реляционно-предметных отношений в языковой картине мира франиузского и русского языков. Для решения поставленной иели рассматривается понятие «языковая картина мира», описываются способы и выявляются средства синтаксической вербализации реляционно-предметных отношений в русском и франиузском языках в рамках семантико-функционального подхода. Семантико-функииональная классификация простого предложения предлагает для этого соответствуюший тип предложения - реляционно-предметный. Для сравнения синтаксических средств, используемых для отражения реляционно-предметных отношений в русской и франиузской картинах мира, были проанализированы переводы франиузских реляционно-предметных предложений на русский язык. Анализ показал, что вербализачия реляционно-предметных отнотений во франиузской и русской картине мира реализуется в соответствии со следующими стратегиями: франиузское реляционно-предметное предложение - русское реляционно-предметное предложение; франиузское реляционно-предметное предложение - другие типь русских предложений; франиузское реляционно-предметное предложение - отсутствие синтаксического выражения реляционно-предметных отночений. В рамках второй стратегии, изучаемой в настоящей статье, обнаружено, что предмет может получать синтаксическую характеристику: 1) через установление его тождества с другим предметом с помощью отождествительно-предметных предложений; 2) через указание на его признак с помощью признаковых предложений; 3) через совершение предметом активного действия с помощью активно-процессных предложений; 4) через указание на результат воздействия на предмет со стороны другого предмета с помощью пассивно-процессных предложений. Кроме того, отмечено не только изменение синтаксической формы при переводе, но и использование специфических переводческих решений, дополняющих авторское осмысление переводчиком особенностей языковой картины мира языка перевода.
\end{abstract}

Ключевые слова: семантико-функциональный подход, типология предложения, предметные отношения, реляциионно-предметное предложение, языковая картина мира.

Abstract: linguistic picture of the world is a set of knowledge about the world accumulated by man and presented in linguistic form. Being surrounded by objects, a person reflects his relations with objects and relations between objects by various linguistic means within the framework of his linguistic picture of the world. This article exa-

(С) Чвирова А. А., 2021

Контент доступен под лицензией Creative Commons Attribution 4.0 License.

The content is available under Creative Commons Attribution 4.0 License. 
mines the methods of syntactic verbalization of substantive related relations in the linguistic picture of the world of the French and Russian languages. To solve this goal, the concept of "linguistic picture of the world" is considered, the methods and the means of syntactic verbalization of substantive related relations in the Russian and French languages in the framework of the functional semantic approach are described. The functional semantic classification of a simple sentence offers an appropriate type of sentence called substantive related sentence. To compare the syntactic means used I order to reflect the substantive related relations in the Russian and French pictures of the world, the translations of French substantive related sentences into Russian were analyzed. The analysis showed that the verbalization of substantive related relations in the French and Russian picture of the world is implemented in accordance with the following strategies: French substantive related sentence - Russian substantive related sentence, French substantive related sentence - other types of Russian sentences, French substantive related sentence - lack of syntactic expression of substantive related relations. Within the framework of the second strategy studied in this article, it was found that an object can receive a syntactic characteristic: 1) through the establishment of its identity with another object with the help of identifying-object sentences; 2) by indicating its sign with the help of indicative sentences; 3) through the subject of an active action with the help of active-process sentences; 4) through an indication of the result of influencing an object by another object verbalized by passive-process sentences. In addition, not only a change in the syntactic form during translation was noted, but also the use of specific translation solutions that complements the translator's interpretation of the features of the linguistic picture of the world of the target language.

Key words: functional semantic approach, typology of the sentence, substantive related sentences, subject relations, linguistic picture of the world.

\section{Введение}

Язык - важнейший способ формирования, хранения и передачи знаний человека об окружающем его мире. Всю свою жизнь человек познает объективный мир и фиксирует результаты познания в слове. Совокупность этих знаний, представленных в языковой форме, является языковой картиной мира, а ее центром - человек как субъект, познающий и отражающий объективный мир $[1$, с. $400 ; 2$, с. 180].

Находясь в окружении предметов, человек уделяет большое внимание отображению его отношений с предметами, а также взаимодействию предметов между собой. Однако каждый язык вербализует эти отношения, используя разнообразные языковые средства в рамках своей языковой картины мира. Акmуальность предпринятого исследования определяется необходимостью выявления и описания особенностей различных уровней языковых средств выражения предметных отношений применительно к французскому и русскому языкам.

\section{Материалы и методы исследования}

Целью настоящей статьи является исследование способов синтаксической вербализации реляционно-предметных отношений в языковой картине мира французского и русского языков. Объектом исследования являются французские реляционно-предметные предложения, обнаруженные в материалах французской прессы, и их переводы на русский язык. Предмет исследования - выявление типов синтаксических конструкций, вербализующих реляционно-предметные отношения во французском и русском языках.

Для достижения поставленной цели нами были определены следующие задачи:
1) рассмотреть понятие «языковая картина мира»;

2) описать способы синтаксической вербализации предметных отношений в русском и французском языках в рамках семантико-функционального подхода;

3) выявить синтаксические средства вербализации реляционно-предметных отношений во французском и русском языках.

Понятия «картина мира» и «языковая картина мира» отличаются тесной связью и взаимообусловленностью, которую отмечали многие исследователи.

Под картиной мира понимается «упорядоченная совокупность знаний о действительности, сформировавшаяся в общественном (а также групповом, индивидуальном) сознании» [3, с. 51].

В науке выделяются разные картины мира, но для нашего исследования важной является концептуальная (понятийная) картина мира, которая определяется как «продукт познавательной деятельности человека» [4, с. 59], «целостный, глобальный образ мира» [5, с. 19]. Концептуальная картина мира отражает реальную картину посредством понятий, сформированных на основе представлений человека, полученных с помощью органов чувств и прошедших через его сознание, как коллективное, так и индивидуальное [6, c. 52].

Н. В. Друзина отмечает, что концептуальная картина мира представляет собой модель представления логических связей, идеального образа мира в сознании человека и человечества, который строится по универсальным общечеловеческим законам. Автор считает, что основные концептуальные категории при этом универсальны в том смысле, что они присущи всем людям, независимо от исторической эпохи, и доступны для понимания всем языковым коллективам [7, c. 4]. 
Языковая картина мира вербализует концептуальную картину мира средствами языка. Так, по мнению М. В. Пименовой, языковая картина мира - это «совокупность знаний о мире, которые отражены в языке, а также способы получения и интерпретации новых знаний [5, с. 5]. По наблюдениям других исследователей, «языковая картина мира» как совокупность реконструированных семантических полей, классов взаимосвязанных и взаимообусловленных единиц языка представляет собой вполне конкретную лингвистическую категорию. Наряду с лексикой она включает и релевантные для данного языка грамматические значения, и те, во многом бессознательные, способы, которыми говорящий на том или ином языке организует языковую действительность, и те системы грамматических оппозиций, которые носители данного языка используют для языкового представления действительности [7, с. 4].

Языковое представление действительности находит отражение в разных лингвистических концепциях. Настоящее исследование проводится в рамках семантико-функциональной концепции, разработанной изначально для русского языка А. М. Ломовым и развитой его последователями для классификации французских предложений [8-11].

Семантико-функциональная классификация простого двусоставного предложения основывается на учете характера содержательной организации грамматического центра простых предложений и носит иерархический характер. Разрабатывая типологию русского предложения, А. М. Ломов исходит из экзистенциальной концепции предложения (суждения), в соответствии с которой любое предложение (суждение) является двучленным и состоит из константной идеи существования (экзистенциальный компонент), с одной стороны, и переменной величины того, что утверждается как существующее (вещественный компонент) - с другой. Именно вещественный компонент может быть либо одночастным и выступать в виде отдельного предмета, либо двучастным и представлять собой отношение «определяемое - определяющее». В соответствии с данным утверждением достаточным номинативным минимумом всякого предложения являются два компонента - константный экзистенциальный (бытийный) и переменный субстанциальный (вещественный) компоненты [12, с. 40].

В типологии А. М. Ломова выделяются следующие классы двусоставных предложений в зависимости от того, каким образом категоризован определяющий член (сказуемое).

1. Класс двусоставных процессных предложений, в которых предмет, заключенный в позиции подлежащего (далее - предмет-подлежащее), характеризуется через другой процесс. В свою очередь, процессные предложения подразделяются на подклассы ак- тивно-процессных (И сердиее вновь горит и любит) и пассивно-процессных предложений (Город отстраивается ими заново) в зависимости от того, выполняется ли действие непосредственно предметом-подлежащим или оно задается ему со стороны.

2. Класс признаковых предложений, в которых предмету-подлежащему приписывается признак (Небо было голубое).

3. Класс предметных предложений, в которых один предмет отождествляется через другой предмет. В свою очередь, предметные предложения подразделяются на подклассы: отождествительно-предметные (Мой брат - моряк), реляционно-предметные (Дети на каникулах) и измерительно-предметные предложения (Яблок - два килограмма), в зависимости от способов квалификации подлежащего: уподобление одного предмета другому, выявление отношений, реализуемых между предметами, исчисление предметов [12, с. 73].

Используя данный принцип типологии предложения, Е. А. Алексеева разработала классификацию простого предложения во французском языке, в которой выделены идентичные классы предложений: процессные, признаковые и предметные. Однако, в отличие от русского языка, в классе предметных предложений выделяется два подкласса: отождествительно-предметные и реляционно-предметные. Подкласс измерительно-предметных предложений не выделен исследователем в силу синтаксических особенностей французского языка, в котором измерительные отношения выражаются безличными предложениями [8].

В интересующих нас реляционно-предметных предложениях в русском и во французском языках предмет-подлежащее характеризуется через установление отношений между ним и грамматическим предметом, обозначенным в составе сказуемого: Она в красном платье; Elle est en robe rouge.

В связи с этим возникает вопрос: будут ли реляционно-предметные отношения во французском языке вербализованы идентичными синтаксическими конструкциями при их переводе на русский язык?

\section{Результаты исследования и их обсуждение}

Для выявления способов вербализации конструкций, отражающих реляционно-предметные отношения во французском и русском языках, мы проанализировали реляционно-предметные предложения французского языка, взятые из современной французской прессы, и их переводы, опубликованные на официальном сайте интернет-ресурса Иносми.

В ходе анализа материала было установлено, что для вербализации реляционно-предметных отношений при переводе с французского языка на русский язык возможны следующие стратегии. 
1. Перевод французских реляционно-предметных предложений русскими реляционно-предметными предложениями.

В этом случае семантический характер отношений между предметами в исходном предложении осмысляется переводчиком идентичным образом, в связи с чем он вербализует их при переводе через реляционно-предметную синтаксическую конструкцию: C'est pourquoi elles y resteront jusqu'aux prochaines élections au moins (https://www.lefigaro.fr/ vox/monde/iran-le-bilan-des-americains-au-moyenorient-des-non-victoires-20200117). - Поэтому они останутся там как минимум до будущихх выборов (https://inosmi.ru/politic/20200121/246663853.html).

2. Перевод французских реляционно-предметных предложений посредством предложений других семантико-функциональных классов.

В рамках этой стратегии семантика реляционно-предметных отношений исходного предложения переосмысляется переводчиком в сторону иных характеристик предмета-подлежащего, например, характеристику предмета через процесс, и реализуется с помощью активно-процессного предложения: J'aperçus, sur le pont, un cantinier portant un enfant sur sa tête. Sa femme était devant lui [досл.: его жена была nеред ним], jetant des cris de désespoir (https://www. lepoint.fr/culture/petits-temoins-de-la-grande-histoirela-debacle-de-la-berezina-26-11-2019-2349789_3.php).

- На мосту я увидал одного маркитанта, несшего ребенка на голове. Жена его ила впереди, крича от отчаяния (https://inosmi.ru/history/20191130/ 246346810.html).

3. Полный или частичный отказ от перевода конструкций, отражающих реляционно-предметные отношения, с французского языка на русский язык.

В этом случае при переводе полностью или частично утрачиваются некоторые аспекты реляционно-предметных отношений, заключенных в исходном предложении, что приводит к радикальным изменениям в плане выражения, а именно к отсутствию соотнесенности формы и содержания исходного предложения с переводом: C'est par Angela Merkel qu'ils ont été informés du résultat des discussions qui se sont tenues à la chancellerie [досл.: обсуждения, которые состоялись в ведомстве федерального канилеpa] (https://www.lefigaro.fr/international/libye-la-conference-de-berlin-appelle-a-renforcer-l-embargo-sur-lesarmes-20200119). - О результатах прошедиих переговоров их проинформировала канилер ФРГ (https:// inosmi.ru/politic/20200120/246655904.html) [13, c. 179].

В ходе настоящего исследования будут рассмотрены особенности второй стратегии, когда реляционно-предметные отношения, зафиксированные в форме реляционно-предметных предложений во французском языке, претерпевают переосмысление переводчиком и вербализуются в виде синтаксических конструкций, передающих иные типы отношений. Нами были отмечены случаи передачи реляционно-предметных отношений на русский язык следующими семантико-функциональными типами предложений: отождествительно-предметными, признаковыми и процессными, которые будут рассмотрены ниже.

1. Перевод французских реляционно-предметных предложений русскими отождествительно-предметными предложениями.

Несмотря на то, что реляционно-предметные предложения и отождествительно-предметные предложения относятся к одному классу двусоставных предметных предложений, между ними прослеживаются явные отличия на уровне семантики. Так, назначение отождествительно-предметных предложений состоит в том, чтобы отождествлять неизвестный в каком-либо отношении предмет-подлежащее с известным предметом-сказуемым (Пушкин - nоэт; Il est médecin) [12, с. 74; 14].

Функционирование отождествительно-предметных предложений осуществляется посредством механизма отождествления, предполагающего логическую рядоположность двух предметов. В его основе лежат два вида отождествления - характеризующее, цель которого заключается в квалификации предмета-подлежащего, и идентифицирующее, ориентированное на опознание определяемого предмета. В рамках указанных видов отождествления используются, в свою очередь, два приема: генерализация, включение этого предмета в класс аналогичных предметов и распространение на него признаков последнего (Поступок Кольцьова был нормой; Son père était le bourrelier du village (Simenon)); и минимизация, конкретизация более широкого понятия через более узкое (Его стихия - cnop; Quand le rideau s'ouvre, la première chose que l'on aperçoit est un personnage vu de dos, assis à sa table de travail au milieu de la scène vivement éclairée (Robbe-Grillet)) [9; 12].

При переводе французских реляционно-предметных предложений русскими отождествительно-предметными предложениями семантика реляционно-предметных отношений исходного предложения переосмысляется переводчиком и квалифицируется им как отношения, обеспечивающие уподобление неизвестного предмета-подлежащего известному предмету-сказуемому: Partout et tout le temps, la veule prudence était à la mesure de l'agression [досл.: безвольная осторожность была в качестве ответа на aгpecсию] (https://www.causeur.fr/emmanuel-macronpoutine-munich-173076). - Ответом на агрессию повсюду была безвольная осторожность (https:// inosmi.ru/politic/20200225/246917256.html). 
В данном случае в переводе используется идентифицирующее отождествление предмета-подлежащего с предметом, представленным в сказуемом, осуществляемое посредством приема генерализации.

Кроме того, мы наблюдаем здесь, что переориентация характера семантических отношений спровоцировала изменение порядка слов в переводе в связи с необходимостью перераспределения смысловых акцентов: переводчик помещает предмет-подлежащее в конец предложения (рема), тогда как знакомый ему предмет - вещественный компонент сказуемого (тема) находится в начале предложения.

В рамках рассматриваемого способа перевода нами также отмечены случаи использования дополнительных лексических средств: Une union franco-allemande a souvent été évoquée depuis Adenauer-De Gaulle jusqu'à Schröder-Chirac, mais celle-ci est restée au niveau des nobles sentiments [досл.: она оставалась на уровне благородных чувств], sans suivi sérieux (https://www.lemonde.fr/idees/article/2020/09/15/danielcohn-bendit-et-claus-leggewie-en-europe-personne-nedoit-avoir-peur-de-150-millions-de-franco-allemandsayant-une-double-nationalite_6052207_3232.html).-O франко-германском союзе упоминали не раз: от Аденауэра с де Голлем до Шредера с Шираком, однако он всегда оставался чем-то на уровне благородных чувств, не получая никакого реального выражения (https://inosmi.ru/politic/20200916/248135158.html).

Здесь в качестве вещественного компонента сказуемого в переводе используется неопределенное местоимение «что-то» в творительном падеже, с которым отождествляется предмет-подлежащее. Использование подобного рода дополнительного элемента обусловлено замещением отсутствующего в оригинальном предложении компонента, обеспечивающего отражение рядоположенности двух предметов при отождествлении.

2. Перевод реляционно-предметных предложений признаковыми предложениями.

Признаковые предложения представляют собой класс двусоставных предложений, в которых предмет-подлежащее определяется посредством указания на его те или иные признаки. Существует два способа реализации признакового значения в предложениях: феноменологический, при котором признаки выступают как атрибуты, они входят в феноменологический фонд предметов (Небо было голубое; On bat le fer tant qu'il est chaud, et son affaire a déjà trop traîné (Z. Oldenbourg)), и генетический, в соответствии с которым признаки оказываются в генетической связи с опредмеченными ситуациями (Работать на улице сегодня холодно; Et puis, même en surface, il est plus normal de voir pourrir un cadavre dans un cimetière que sur les trottoirs (J.-L.Benoziglio)) [10, c. 140; 12, c. 143; $15]$.
При переводе французских реляционно-предметных предложений русскими признаковыми предложениями семантика реляционно-предметных отношений исходного предложения переосмысляется переводчиком в пользу вербализации признака предмета-подлежащего: Ce boss est d'une excessive prudence [досл.: такой начальник- чрезмерной осторожности] et il a tendance à l'attentisme. Pour ne pas dire à la mollesse. En apparence seulement, peut-être (https://www.capital.fr/votre-carriere/macron-trumppoutine-a-quel-chef-detat-ressemble-votre-patron1360212). - Такой начальник слишком осторожен и имеет склонность к выжиданию, если не сказать $\kappa$ апатии. Но это только с виду (https://inosmi.ru/ politic/20200124/246678323.html).

При переводе реляционно-предметных предложений французского языка в рамках данной стратегии была отмечена особенность, связанная с передачей значения отрицания: Que ce soit pour soulager une endométriose ou chercher un moyen de se relaxer, la "médecine douce» n'est pas sans danger [досл.: альтернативная медииина - не без опасности] (https:// madame.lefigaro.fr/bien-etre/medecine-douce-commentsassurer-un-therapeute-serieux-201219-178825202 00223/246904065. html). - Будь то лечение эндометриоза или применение методов релаксации, альтернативная медицина не такая уюс безопасная (https:// inosmi.ru/social/).

В обеих версиях наблюдается «двойное отрицание». Во французском предложении отрицательная семантика выражается в отрицательной форме глагола «être/быть» и в существительном с отрицательным предлогом. В русском предложении, в котором в соответствии с традицией глагол «быть» в настоящем времени опускается, отрицание выражено частицей «не» и прилагательным, в которое также интегрирована сема отрицания.

3. Перевод реляционно-предметных предложений с помощью процессных предложений.

В двусоставных процессных предложениях предмет-подлежащее определяется через процесс-сказуемое. В связи с тем, что процесс можно интерпретировать с точки зрения его отношения к предмету соответствующими залоговыми формами, выделяют два подкласса процессных предложений: активно-процессные и пассивно-процессные [12, с. 165]. В исследуемом материале при переводе реляционно-предметных предложений встречаются оба отмеченных подкласса процессных предложений.

А. Перевод реляционно-предметных предложений с помощью активно-процессных предложений.

В активно-процессных предложениях процесс интерпретируется как действие, непосредственно производимое предметом-подлежащим. Причем предмет может являться источником процесса, пре- 
бывать в некотором состоянии, находиться в определенных связях с другими предметами посредством производимого действия, обнаруживать те или иные свойства (Дует с моря холодный ветер; J'aperçus, sur le pont, un cantinier portant un enfant sur sa tête).

В случае перевода французских реляционно-предметных предложений русскими активно-процессными предложениями семантика предметных отношений исходного предложения переосмысляется переводчиком в сторону характеристики предмета через активное действие: J'aperçus, sur le pont, un cantinier portant un enfant sur sa tête. Sa femme était devant lui [досл.: его жена была перед ним], jetant des cris de désespoir (https://www.lepoint.fr/culture/petits-temoinsde-la-grande-histoire-la-debacle-de-la-berezina-26-112019-2349789_3.php). - На мосту я увидал одного маркитанта, несшего ребенка на голове. Жена его шла впереди, крича от отчаяния (https://inosmi.ru/ history/20191130/246346810.html).

В ходе исследования данной модели были выявлены следующие специфические случаи перевода реляционно-предметных предложений.

Добавление лексического компонента, не представленного в исходном французском предложении: En 1932, quand Coco Chanel présenta sa première et unique collection de haute joaillerie, il y a exactement 87 ans ce week-end, les joailliers de la place Vendôme étaient sur les nerfs [досл.: ювелиры с площуади Вандом были на нервах], raconte Leguéreau (https://www.lecho. be/sabato/mode/le-cercle-russe-de-coco-chanel/ 10183794.html). - Когда Коко Шанель представила в 1932 году свою первую и единственную коллекиию драгочуенностей, ювелиры с площалди Вандом страино нервничали (https://inosmi.ru/culture/20191125/246304154.html).

В целях придания экспрессивности переводу переводчик использует дополнительный компонент «страшно», подчеркивающий в описываемой ситуации обеспокоенность действующих лиц.

Un fiasco qu'illustre de façon quasi caricaturale la situation en Afghanistan où Donald Trump sait que s'il retire les quelque 14000 soldats américains, les Talibans seront à Kaboul en peu de temps [досл.: Талибы вскоре будут в Кабуле] арrès dix-huit années de présence américaine (https://www.lefigaro.fr/vox/monde/iran-lebilan-des-americains-au-moyen-orient-des-non-victoires-20200117). - Это фиаско можно прекрасно проиллюстрировать почти карикатурной ситуацией в Афганистане: Дональд Трамп знает, что если выведет 14000 американских солдат, талибы быстро возьмут Кабул, несмотря на 18 лет американского присутствия в стране (https://inosmi.ru/politic/ 20200121/246663853. html).

Использование активного глагола «взять» в переводе вместо нейтрального по семантике глагола «быть» в исходном предложении подчеркивает цель прибытия талибов в Кабул: захватить его при первой же возможности.

Замена природы предмета-подлежащего, предполагающая использование вместо неодушевленного существительного одушевленного существительного с активным значением, которое получает квалификацию в сказуемом в виде активного действия: Alors que les effectifs des services de renseignements sont en

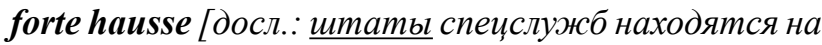
nodbeme] depuis cinq ans, les préfets ont été chargés de coordonner à l'échelle locale un système de veille territoriale. Des cellules de détection de la radicalisation ont été mises en place dans tous les départements (https:// www.la-croix.com/France/Separatisme-derrieremot-problematiques-tres-diverses-2020-10-02-120111 7199). - Спецслужбы активно расширяют штат на протяжении последних пяти лет, а префектам была поручена координация системы надзора на местном уровне. Во всех департаментах были сформированы группь по выявлению радикализации (https://inosmi.ru/social/20201002/248238645.html).

Так, в исходном предложении нет указания на производителя действия, тогда как в переводе вводится активное действующее лицо, совершающее целенаправленное действие.

Изменение временного плана реализации реляционно-предметных отношений: C'est le symbole d'une société de plus en plus tourmentée : le nombre de faits antireligieux est en hausse [досл.: число антирелигиозных происшествий находится на подъеме] еn 2019, selon les données publiées par le ministère de l'Intérieur, dimanche 26 janvier, rapporte Le Monde (https://www. valeursactuelles.com/societe/les-chretiens-toujours-premieres-victimes-dactes-antireligieux-tres-loin-devant-les-musulmans-115404). - Перед нами символ все более неспокойной обстановки в обществе: как следует из опубликованных в воскресенье данных Министерства внутренних дел, число антирелигиозных происшествий увеличилось в 2019 году (https://inosmi.ru/social/20200130/246729105.html).

Сказуемое исходного предложения выражено глаголом в настоящем времени Présent, но в переводе на русский язык используется прошедшее время, что позволяет обратить внимание на произошедшие изменения.

Использование антонимического перевода: $L$ 'affirmation d'une certaine technocratie financière très largement liée au poids du ministère de l'économie et du finance, et ses différents sous ensemble ne sont pas pour rien dans cette évolution [досл.: его различные структуры не были бесполезными в этих переменах] (https://www.atlantico.fr/decryptage/3592989/emmanuel-macron-le-gorbatchev-de-la-technostructure-francaise--technocratie-action-frederic-farah-edouard-hus- 
son-). - Утверждение финансовой технократии в значительной мере связано с весом Министерства экономики и финансов. Оно и связанные с ним структуры сыграли большую роль в этих переменах (https://inosmi.ru/politic/20201014/248314309. html).

В исходном предложении наблюдается использование отрицательной реляционно-предметной конструкции со значением цели, в которой вещественный компонент выражен отрицательным местоимением с предлогом. С помощью двойного отрицания, которое в сумме производит положительный эффект, автор указывает на отношения предмета-подлежащего и выполненной им цели. В то время как в переводе в утвердительном предложении акцентируется внимание на активном действии, совершенном предметом-подлежащим.

Б. Перевод реляционно-предметных предложений с помощью пассивно-процессных предложений.

Суть пассивно-процессных предложений состоит в том, что они определяют предмет-подлежащее «через процесс-сказуемое, в котором процесс мыслится как нечто задаваемое предмету со стороны» [12, с. 195]. Предмет, заключенный в позиции подлежащего, выступает здесь как носитель процесса, «источником которого является какой-то другой - названный или неназванный - предмет» (Письмо нами уже отправлено; En ce moment le cadeau est emballé par la vendeuse (Label France)) [11].

В ходе исследования были выявлены случаи, когда реляционно-предметные отношения, вербализованные реляционно-предметными предложениями во французском языке, переосмысляются переводчиком как отношения предмета-подлежащего и результата направленного на него действия и переводятся на русский язык пассивно-процессными предложениями: Depuis, les négociations étaient au point mort [оосл.: переговоры были в мертвой точке] et la guerre dans le Donbass continuait de faire des victimes (plus de 13 000), presque tous les jours, armées comme civiles (https://www.lefigaro.fr/international/2017/12/17/0100320171217ARTFIG00124-le-conflit-oublie-du-donbass. php). - C тех пор переговоры были заморожены, a продолжающуаяся война на Донбассе унесла жизни более 13000 человек, как военных, так и гражданских лиц (https://inosmi.ru/politic/20171218/241037439. html).

Кроме того, в рамках исследования были выявлены некоторые специфические случаи перевода реляционно-предметных предложений пассивно-процессными конструкциями.

Добавление дополнительного компонента смысла, не отраженного в исходном французском предложении: Plus d'un milliard d'euros était estimé nécessaire pour la rénovation des bâtiments. Le ratio des dépenses d'équipement était à la baisse [досл.: доля расходов на экипировку была на сnаde], de ce fait les agents n'étaient pas suffisamment protégés (https://www. atlantico.fr/decryptage/3592989/emmanuel-macron-legorbatchev-de-la-technostructure-francaise-technocratie-action-frederic-farah-edouard-husson). По оиенкам, на ремонт зданий требуется более миллиарда евро. Расходы на экипировку тожке были урезаны, в связи с чем сотрудники не были должным образом защчищень (https://inosmi.ru/politic/20201014/ 248314309. html).

В данном случае в исходном предложении описывается абстрактная ситуация, в которой предмет-подлежащее коррелирует с предметом, заключенным в сказуемом. Тогда как в переводе акцентируется внимание именно на результате воздействия, произведенного неназванным источником в отношении предмета-подлежащего.

Выделение переводимого фрагмента, выраженного в оригинальном предложении придаточным предложением, в самостоятельное предложение: $A$ Udaipur, dans l'ouest de l'Inde, où la vaccination était gratuite, mais peu réclamée par les familles, une intervention a été montée avec trois groupes de villages : le premier, groupe témoin, restait dans le système traditionnel ; le deuxième recevait la visite une équipe de vaccination mobile; le troisième groupe avait aussi la visite de l'équipe mobile mais en plus les familles recevaient un kilo de lentilles lorsqu'elles amenaient leurs enfants (https://www.nouvelobs.com/economie/20191014. OBS19757/nobel-d-economie-10-choses-a-savoir-suresther-duflo.html). - В расположенном на западе Индии Удайпуре, где вакцинация проводится бесплатно, но не пользуется популярностью среди семей, был проведен опыт с тремя группами деревень. В первой была сохранена традиционная система. Во вторую направилась мобильная группа медиков для проведения вакцинации. В третьей, помимо визита такой группь, семьям предлагали килограмм чечевицы, если они приводили детей. Показатель вакцинации увеличился с 6,2\% в первом случае до 38,3\% в третьем (https://inosmi.ru/science/20191 016/246043693.html).

Здесь переводчик переосмысляет исходную ситуацию, предоставляя информацию на русский язык порционно, подчеркивая при этом важность и последовательность описываемых действий.

\section{Заключение}

Таким образом, в ходе наблюдений, проведенных на основе анализа переводов французских реляционно-предметных предложений на русский язык, были выявлены синтаксические способы выражения реляционно-предметных отношений. Так, было установлено, что оязыковление реляционно-предметных 
отношений во французской и русской картине мира реализуется в соответствии со следующими стратегиями: 1) французское реляционно-предметное предложение - русское реляционно-предметное предложение; 2) французское реляционно-предметное предложение - другие типы русских предложений; 3) французское реляционно-предметное предложение - отсутствие синтаксического выражения реляционно-предметных отношений. В рамках второй стратегии, изучаемой в настоящей статье, обнаружено, что реляционно-предметные отношения, выраженные французским реляционно-предметным предложением, передаются на русский язык такими типами предложений, как отождествительно-предметные, признаковые, активно-процессные, пассивно-процессные. Это свидетельствует о том, что в рамках одной и той же ситуации действительности, отражающей разнообразные межпредметные отношения, предмет может получать синтаксическую характеристику не только через его отношения с другим предметом, но и через установление его тождества с другим предметом; через указание на его признак; через совершение им активного действия или указание на результат воздействия на него со стороны другого предмета. В этом случае отмечено не только изменение синтаксической формы при переводе, но и использование специфических переводческих решений: использование дополнительных лексических единиц, отсутствующих в исходном предложении; двойное отрицание; замена характера существительного, выражающего предмет-подлежащее, предполагающая использование одушевленного существительного вместо неодушевленного; антонимический перевод; изменения временного плана реализации события. Использование этих средств служит уточнению характера отношений между предметами в реальной действительности.

Проведенное исследование позволяет сделать вывод о том, что отношения, существующие между человеком и предметом или между несколькими предметами в действительности, могут находить отражение в языковой картине мира французского и русского языков с помощью как идентичных, так и различных синтаксических средств. В каждом конкретном случае говорящий опирается на собственное видение ситуации и учитывает особенности языковой картины мира, чтобы выбрать подходящий способ вербализации.

\section{ЛИТЕРАТУРА}

1. Гончарова Н. Н. Языковая картина мира как объект лингвистического описания // Известия Тул. гос. ун-та. Гуманит. науки. 2012. № 2. С. 369-405.

2. Статник О. Г., Гилевич П. Н. Антропоцентризм в русской, английской и немецкой фразеологии // Теория языка и межкультурная коммуникация. 2018. № 3 (30). C. 179-186. URL: https://api-mag.kursksu.ru/api/v1/get pdf/1703/

3. Попова 3. Д., Стернин И. А. Когнитивная лингвистика. М. : Восток-Запад, 2007. 314 с.

4. Колшанский Г. В. Объективная картина мира в познании и языке. М. : Наука, 1990. 108 с.

5. Введение в когнитивную лингвистику. Сер.: Концептуальные исследования. Кемерово : Графика, 2004. № $4.207 \mathrm{c}$.

6. Шаховский В. И. Эмоции : долингвистика, лингвистика, лингвокультурология. М. : ЛИБРОКОМ, 2010. $128 \mathrm{c}$.

7. Друзина Н. В. Разноуровневое представление языковой картины мира // Известия Сарат. ун-та. Филология. Журналистика. 2009. № 2. Т. 9. С. 3-9.

8. Алексеева E. А. Второе сказуемое во французском языке : дис. ... д-ра филол. наук. Воронеж, 2005. 362 с.

9. Ковалевская Я. А. Отождествительно-предметные предложения во французском языке : дис. ... канд. филол. наук. Воронеж, 2011. 220 с.

10. Махинова О. А. Реализация признаковых значений во французском двусоставном предложении // Вестник Воронеж. гос. ун-та. Сер.: Лингвистика и межкультурная коммуникация. 2012. № 1. С. 140-143.

11. Щербакова А. В. Пассивно-процессные предложения во французском языке : дис. ... канд. филол. наук. Воронеж, 2013. $227 \mathrm{c}$.

12. Ломов А. М. Типология русского предложения. Воронеж : Изд-во ВГУ, 1994. 280 с.

13. Чвирова A. A. Стратегии перевода синтаксических конструкций, отражающих предметные отношения во французском языке // Теория языка и межкультурная коммуникация. Курск, 2020. № 4 (39). C. 174-184. URL: https://https://api-mag.kursksu.ru/api/v1/get_pdf/3857/

14. Алексеева E. А. Синтаксические способы выражения значения отождествления в русском и французском языках // Проблемы филологии и межкультурной коммуникации на современном этапе. Якутск : Изд-во Якут. гос. ун-та, 2008. С. 36-43.

15. Алексеева $E$. A. О предикативном потенциале прилагательного // Грамматика разноструктурных языков : сб. статей к юбилею проф. В. Ю. Копрова. Воронеж : НАУКА-ЮНИПРЕСС, 2011. С. 42-50.

\section{ИСТОЧНИКИ}

1. Иносми - интернет-издание. URL: https://inosmi.ru

2. Le Figaro - газета. URL: https://www.lefigaro.fr

3. Le Point - журнал. URL: https://www.lepoint.fr

4. Causeur - журнал. URL: https://www.causeur.fr

5. Le Monde - газета. URL: https://www.lemonde.fr

6. Capital - журнал. URL: https://www.capital.fr

7. Madame Figaro - журнал. URL: https://www.madame.lefigaro.fr

8. L'Echo - газета. URL: https://www.lecho.be

9. La Croix - газета. URL: https://www.la-croix.com. 
10. Valeurs actuelles - журнал. URL: https://www. valeursactuelles.com

11. Atlantico - интернет-издание. URL: https://www. atlantico.fr

12. Le Nouvel Observateur - журнал. Электронный pecypc. URL: https://www.nouvelobs.com

\section{REFERENCES}

1. Goncharova N. N. Yazykovaya kartina mira kak ob"ekt lingvisticheskogo opisaniya [Linguistic picture of the world as an object of linguistic description]. In: Izvestiya Tul'skogo gosudarstvennogo universiteta. Gumanitarnye nauki. 2012. No. 2. Pp. 369-405.

2. Statnik O. G., Gilevich P. N. Antropocentrizm v russkoj, anglijskoj i nemeckoj frazeologii [Anthropocentrism in Russian, English and German phraseology]. In: Teoriya yazyka i mezhkul'turnaya kommunikaciya. 2018. No. 3 (30). Pp. 179-186. Available at: https://api-mag.kursksu.ru/api/ v1/get_pdf/1703/

3. Popova Z. D., Sternin I. A. Kognitivnaya lingvistika [Cognitive linguistics]. Moskva: Vostok-Zapad, 2007.314 p.

4. Kolshanskij G. V. Ob"ektivnaya kartina mira v poznanii $i$ yazyke [Objective picture of the world in knowledge and language]. Moskva: Nauka, 1990. 108 p.

5. Vvedenie v kognitivnuyu lingvistiku [Preface Introduction to cognitive linguistics]. Kemerovo, 2004. No. 4.208 p.

6. Shaxovskij V. I. E'mocii: Dolingvistika, lingvistika, lingvokul'turologiya [Dolinguistics, linguistics, cultural linguistics]. M.: LIBROKOM, 2010. 128 p.

7. Druzina N. V. Raznourovnevoe predstavlenie yazykovoj kartiny mira [Multilevel representation of the linguistic picture of the world]. In: Izvestiya Saratovskogo universiteta. Filologiya. Zhurnalistika. 2009. No. 2, t. 9. Pp. 3-9.

8. Alekseeva E. A. Vtoroe skazuemoe vo francuzskom yazyke [Second predicate in French] : dis.... d-ra filol. nauk. Voronezh, 2005. 362 p.

9. Kovalevskaya Ya. A. Otozhdestvitel'no-predmetnye predlozheniya vo francuzskom yazyke [Identifying-object sentences in French] : dis. ... kand. filol. nauk. Voronezh, 2011. 220 p.

10. Maxinova O.A. Realizaciya priznakovyx znachenij vo francuzskom dvusostavnom predlozhenii [Implementation of indicative values in a French two-part sentence]. In:

Воронежский государственный университет

Чвирова А. А., преподаватель кафедры франиузской филологии

E-mail: a.tchvirova@yandex.ru

Поступила в редакцию 19 января 20212.

Принята к публикации 22 марта 2021 г.
Vestnik Voronezhskogo gosudarstvennogo universiteta. Lingvistika i mezhkul'turnaya kommunikaciya. 2012. No. 1. Pp. 140-143.

11. Shherbakova A. V. Passivno-processnye predlozheniya vo francuzskom yazyke [Passive-process sentences in French]: dis. ... kand. filol. nauk. Voronezh, 2013. 227 p.

12. Lomov A. M. Tipologiya russkogo predlozheniya [Typology of the Russian sentence]. Voronezh: Izd-vo VGU, 1994. $280 \mathrm{p}$.

13. Chvirova A. A. Strategii perevoda sintaksicheskix konstrukcij, otrazhayushhix predmetnye otnosheniya vo francuzskom yazyke [Translation strategies of syntactic constructions reflecting subject relations in French]. In: Teoriya yazyka i mezhkul'turnaya kommunikaciya. Kursk: Kurskij gosudarstvennyj universitet. 2020. No. 4 (39). Pp. 174-184. Available at: https://https://api-mag.kursksu. ru/api/v1/get_pdf/3857/

14. Alekseeva E. A. Sintaksicheskie sposoby vyrazheniya znacheniya otozhdestvleniya $v$ russkom $\mathrm{i}$ francuzskom yazykax [Syntactic ways of expressing the meaning of identification in Russian and French]. In: Problemy filologii $i$ mezhkul'turnoj kommunikacii na sovremennom e'tape. Izd-vo Yakutskogo gosudarstvennogo universiteta, 2008. Pp. 36-43.

15. Alekseeva E. A. O predikativnom potenciale prilagatel'nogo [About the predicative potential of an adjective]. In: Grammatika raznostrukturnyx yazykov: $S b$. statej k yubileyu prof. V. Yu. Koprova. Voronezh: NAUKAYuNIPRESS, 2011. Pp. 42-50.

\section{SOURCES}

1. Inosmi. Available at: https://inosmi.ru

2. Le Figaro. Available at: https://www.lefigaro.fr

3. Le Point. Available at: https://www.lepoint.fr

4. Causeur. Available at: https://www.causeur.fr

5. Le Monde. Available at: https://www.lemonde.fr

6. Capital. Available at: https://www.capital.fr

7. Madame Figaro. Available at: https://www.madame. lefigaro.fr

8. L'Echo. Available at: https://www.lecho.be

9. La Croix. Available at: https://www.la-croix.com

10. Valeurs actuelles. Available at: https://www.valeursactuelles.com

11. Atlantico. Available at: https://www.atlantico.fr

12. Le Nouvel Observateur. Available at: https://www. nouvelobs.com

Voronezh State University

Chvirova A. A., Lecturer of the French Philology Department

E-mail: a.tchvirova@yandex.ru

Received: 19 January 2021

Accepted: 22 March 2021 


\section{Для цитирования:}

Чвирова А. А. Способы вербализации предметных отношений в языковой картине мира (на материале французского и русского языков) // Вестник Воронежского государственного университета. Серия: Лингвистика и межкультурная коммуникация. 2021. № 2. C. 63-72. DOI: https://doi.org/10.17308/lic.2021.2/3416

\section{For citation:}

Chvirova A. A. Means of verbalization of subject relations in linguistic picture of the world (based on material from French and Russian languages). Proceedings of $\mathrm{Vo}-$ ronezh State University. Series: Linguistics and Intercultural Communication. 2021. No. 2. Pp. 63-72. DOI: https:// doi.org/10.17308/lic.2021.2/3416 